\title{
CRIMINOLOGIA E CONDENAÇÃO PREEXISTENTE: SOB A ÓTICA DA CRIANÇA E DO ADOLESCENTE
}

\author{
Eliane Alves de Oliveira* \\ Orientador: Bruno A. Souza**
}

\section{RESUMO}

$\mathrm{O}$ artigo busca exprimir, nas entrelinhas do estudo interdisciplinar da criminologia, os motivos que levam uma criança ou um adolescente a cometer atos infracionais. Assim, ao utilizar o método quantitativo e qualitativo visa demonstrar o implícito prejulgamento da sociedade e Estado em razão das desigualdades sociais, em torno dos que já cometeram anteriormente condutas delituosas e aqueles que tragicamente ostentam esse título, sem a observância preliminar do caso concreto. Nesse mesmo viés, demonstra o etiquetamento que há em determinados grupos, nos quais, em razão da imposição social, se permite condenações preexistentes pautadas em caráter discriminatório, violando, sobremaneira, princípios constitucionais. Abrange, ainda, quais são as atribuições da família e do Estado no quesito formação e desenvolvimento psicossocial da criança e do adolescente e até onde deve-se reconhecer a extensão de sua responsabilidade. Para tanto, observa a evolução nos direitos da infância e juventude, destacando quais são as medidas protetivas e socioeducativas e, se de fato o sistema carcerário (Fundação Casa) alcança sua finalidade pedagógica para a reabilitação dos adolescentes, gerando assim modificação no comportamento e evitando sua reincidência.

Palavras-chave: Criança e Adolescente. Condenação preexistente. Ato infracional. Criminologia. Medidas socioeducativas.

\section{CRIMINOLOGÍA Y DAÑOS PREEXISTENTES: \\ DESDE LA PERSPECTIVA DE LA NIÑEZ Y LA ADOLESCENCIA}

\section{RESUMEN}

El artículo busca expresar, entre las líneas del estudio interdisciplinario de la criminología, las razones que llevan a un niño, niña o adolescente a cometer infracciones. Así, al utilizar el método cuantitativo y cualitativo, se pretende demostrar el prejuzgamiento implícito de la sociedad y el Estado por las desigualdades sociales, en torno a quienes han cometido previamente una conducta delictiva y a quienes trágicamente llevan ese título, sin observar de

* Bacharel em Direito pela Universidade Metodista de São Paulo. E-mail: elialves.oliveira@icloud. com.

** Advogado. Professor, de Direito Penal e Processo Penal da Universidade Metodista de São Paulo. Pós-graduado em Direito Penal e Direito Processual Penal pela Faculdade Damásio de Jesus. Mestrando em Direito da Saúde, pela Universidade Santa Cecília. E-mail: souz_abruno@outlook.com. 
manera preliminar el caso específico. En la misma línea, el etiquetado que existe en determinados colectivos, donde, por la imposición social, se permiten condenas preexistentes basadas en el carácter discriminatorio, violando, sobre todo, principios constitucionales. También cubre cuáles son los deberes de la familia y del Estado en materia de formación y desarrollo psicosocial de la niñez y la adolescencia, y hasta qué punto debe reconocerse el alcance de su responsabilidad. Para ello, observará la evolución de los derechos de la niñez y la juventud, destacando cuáles son las medidas protectoras y socioeducativas y, si efectivamente el sistema penitenciario (Fundação Casa) logra su propósito pedagógico para la rehabilitación de los adolescentes, generando así cambios de comportamiento y evitando su recurrencia.

Palabras-clave: Niño y adolescente. Condena preexistente. Acto infractor. Criminología. Medidas educativas.

\section{INTRODUÇÃO}

O presente trabalho percorre pela evolução histórica nos direitos da Criança e do Adolescente, que passam de desproteção à proteção integral e prioritária, sendo sujeitos de direitos, em condição de desenvolvimento e prioridade absoluta.

Aborda o Estatuto da Criança e do Adolescente que disciplina sobre os direitos fundamentais, estabelecendo diferenciação entre o público carente e o que tenha cometido algum ato infracional. Define medidas protetivas para aqueles que tenham seus direitos ameaçados ou violados e medidas socioeducativas para aqueles que estejam em conflito com a lei.

O estudo ainda traz algumas possíveis causas da prática do ato infracional, ou seja, por que crianças e adolescentes tendem a praticar crimes.

Para tanto, a pesquisa buscará compreender, a partir do estudo interdisciplinar da criminologia, qual é a origem do crime, entendendo o delito, o delinquente, a vítima e o efeito social do ato.

Além disso, visa examinar se os fatores externos, são influenciadores na formação da criança e do adolescente, sobretudo, porque são determinantes para a ocorrência de atos infracionais. Reforça a vulnerabilidade e a influência de terceiros e chama atenção para a necessidade de serem devidamente assistidos, com seus direitos assegurados.

Nesse mesmo viés, trará a transparente ineficiência do Estado no equilíbrio social e, por consequência um prejulgamento antecipado da sociedade em torno da juventude brasileira. Noutras palavras, aponta o etiquetamento de determinados grupos, o que viabiliza factualmente de forma contínua condenações equivocadas.

Buscará demonstrar se o sistema carcerário Fundação Casa, cuja incumbência é de aplicar as medidas socioeducativas de privação de liberdade e semiliberdade ao adolescente que tenha praticado algum ato infracional, atinge sua finalidade de reabilitação, gerando por conseguinte modificação no comportamento do mesmo, evitando sua futura reincidência, oportunizando caminhos diferentes a serem seguidos.

Assim, acrescente-se o dever, inclusive, da família, para em aquiescência com o Estado, realize projetos que sejam (efetivamente) capazes de proporcionar à 
criança e ao adolescente uma oportunidade de vida diferente daquela que trilhou até que chegasse a cometer atos infracionais. Inversamente, de ações que permitam a reabilitação daqueles que já se encontram na criminalidade.

\section{EVOLUÇÃO NOS DIREITOS DA CRIANÇA E DO ADOLESCENTE}

Objetiva-se na primeira seção adentrar em normas voltadas para assegurar direitos e garantias da criança e do adolescente, certo de que são sujeitos de direitos, em condição de desenvolvimento, bem como objetos de prioridade absoluta da família, sociedade e Estado.

Em 1927, surge o Código Mello Matos, também conhecido como Código de Menores, que visava o amparo da criança e do adolescente de acordo com o binômio de carência-delinquência, o que se confundia com descriminalização da infância pobre.

Após 50 anos da promulgação do Código Mello Mattos, é criado um novo Código de Menores, em 1979, com a proposta de uma mudança filosófica no tratamento do menor autor de infração penal.

Segundo Leal,

Contrários ao uso de termos alegadamente pejorativos como "abandonado" e "delinquente", presentes no Código Mello Mattos, os legisladores do novo Código optaram pela expressão "menor em situação irregular" [...]. (LEAL, 2001, p. 187- grifo nosso).

Portanto, a chegada de um novo código foi justamente para substituir conceitos, retirar do ordenamento jurídico terminologias pejorativas, tais como abandonado e delinquente, e substituí-los pela expressão de menor em situação irregular.

Destaca-se que, menores em situação irregular não eram somente aqueles que cometiam algum ato infracional, mas também, aqueles que não recebiam a devida assistência, proteção de sua família.

Diante disso, a Constituição Federal de 1988 reforçou a necessidade da substituição do Código de Menores por uma legislação que destinasse para todas as crianças (até 12 anos incompletos) e adolescentes (entre 12 e 18 incompletos), o tratamento correto, sendo sujeitos de direitos, em condição de desenvolvimento e objetos de prioridade absoluta.

Assim, dotado de inovação nasce o Estatuto da Criança e do Adolescente, o ECA, Lei no 8.069, de 1990, que substitui o Código de Menores e a situação irregular, abraçando a proteção integral, defendida pela ONU.

Assegura Leal que:

Inovador, o Estatuto catalogou os direitos fundamentais das crianças e dos adolescentes e estabeleceu a municipalização do atendimento, com participação da sociedade organizada, seja na formulação das políticas públicas para a infância e a juventude, seja no controle das ações, criando os Conselhos dos Direitos da Criança e do Adolescente e os Conselhos Tutelares. (LEAL, 2001, p. 189). 
A doutrina de situação irregular, perdurou por quase todo século XX, e ela deixava crianças e adolescentes à mercê das políticas sociais. Com entendimento diferente, a doutrina de proteção integral visava amparar todas as crianças e adolescentes como sendo sujeitos de direito, acabando com as discriminações antes vivenciadas.

O Estatuto estabeleceu diferenciação entre crianças e adolescentes carentes daqueles que tenham cometido algum ato infracional. Para a primeira, o ECA estabelece medidas protetivas, enquanto para a segunda, indica o atendimento socioeducativo, acabando definitivamente com as controvérsias vivenciadas nas normas anteriores.

O Estatuto inseriu no ordenamento jurídico o tríplice sistema de garantias, sendo eles: Sistema Primário de Garantias Universais, que assegura políticas de atendimento em caráter preventivo; Sistema Secundário ou proteção especial, tratando das medidas de proteção destinadas às crianças e adolescentes em situações de risco, não autores de atos infracionais; Sistema Terciário de Garantias, que estabelece proteção aos jovens em conflito com a lei, tratando das medidas socioeducativas.

Estabeleceu que ato infracional é a conduta descrita como crime ou contravenção penal tipificada no Código Penal.

As medidas socioeducativas, visam a reintegração familiar e comunitária e sua aplicação deverá ser individualizada, de acordo com a capacidade do jovem em cumpri-la, sempre observando as circunstâncias e gravidade da infração. Poderão ser aplicadas isoladamente ou cumulativamente, com possibilidade de serem substituídas a qualquer tempo por autoridade competente se assim julgar necessário.

\section{DA JUSTIÇA RESTAURATIVA ÀS MEDIDAS SOCIOEDUCATIVAS}

A expressão Justiça Restaurativa foi utilizada pela primeira vez em 1977 pelo psicólogo americano Albert Eglash. Ele sustentou em seu artigo intitulado Beyond Restitution: Creative Restitution que havia três respostas ao crime: a retributiva, baseada na punição; a distributiva, focada na reeducação; e a restaurativa, cujo fundamento seria a reparação (BRANDÃO, 2010).

Ela é vista como "uma luz no fim do túnel", pois é uma fuga da tradicional e obsoleta justiça retributiva, para um novo enfoque de possíveis soluções aos problemas de violência e criminalidade no mundo, indo ao encontro de punições justas e renovação de esperança.

Para tanto, o crime/ato infracional, na Justiça Restaurativa, não é apenas uma conduta típica, antijurídica e culpável que atenta contra bens e interesses penalmente tutelados, mas, antes disso, é uma violação nas relações entre vítima, infrator e a comunidade. Cabe à Justiça identificar as necessidades e obrigações derivadas dessa violação e do trauma causado, oportunizar e encorajar pessoas envolvidas a dialogarem e chegarem em um acordo, como sujeitos centrais do processo. 
Sendo ela, a Justiça, avaliada segundo sua capacidade de fazer com que as responsabilidades pelo cometimento do delito sejam assumidas, as necessidades oriundas da ofensa devem ser satisfatoriamente atendidas e o resultado individual e social, alcançado. (PINTO, 2011).

Portanto, a Justiça Restaurativa é um complemento ao sistema jurisdicional, uma justiça participativa, com finalidade de operar real transformação; com soluções compartilhadas e uma nova forma de promoção dos direitos humanos e da cidadania, da inclusão e paz social.

O maior desafio que se enxerga com a justiça restaurativa é exatamente o de mudança de paradigma, alteração de olhar, desapegando-se da lente meramente retributiva, para que assim ocorram transformações nas pessoas e perspectivas.

A ideia principal é voltar-se para o futuro e para a restauração dos relacionamentos, ao invés de emergir somente no passado e na culpa. A justiça convencional diz: você fez isso e tem que ser castigado! A justiça restaurativa pergunta: o que você pode fazer agora para restaurar isso? (PINTO, 2011).

Um marco para o público infanto-juvenil se deu em 2005, com a implementação da Justiça Restaurativa no estado de São Paulo, na cidade de São Caetano do Sul. O projeto foi coordenado pelo Juiz Eduardo Rezende Melo, da $1^{\text {a }}$ Vara da Infância e Juventude. Melo, Ednir e Yazbek retratam abaixo os objetivos primordiais deste projeto:

\begin{abstract}
A resolução de conflitos de modo preventivo nas escolas, evitando seu encaminhamento à justiça - já que uma grande parte dos Boletins de Ocorrência recebidos pelo Fórum provinha de escolas - com a consequente estigmatização que diversos estudos apontam como decorrência do envolvimento de adolescentes com o sistema de justiça;

A resolução de conflitos caracterizados como atos infracionais e não relacionados à vivência comunitária escolar, no Fórum, em círculos restaurativos;

O fortalecimento de redes comunitárias, para que agentes governamentais e não governamentais, de organizações voltadas a assegurar os direitos da Infância e da Juventude, pudessem passar a atuar de forma articulada, no atendimento às necessidades das crianças, adolescentes e suas famílias, identificadas, principalmente, por meio de escolas. (MELO; EDNIR; YAZBEK, 2008, p. 13 - grifo nosso).
\end{abstract}

Onze escolas municipais de São Caetano do Sul foram preparadas para a interação com o sistema judiciário e para lidar com a nova metodologia. Nos três primeiros anos do projeto (2005-2007), as práticas restaurativas nas escolas geraram: 160 círculos restaurativos realizados, 153 acordos (100\% deles cumpridos), 317 pessoas envolvidas, 330 acompanhantes da comunidade e 647 participantes dos círculos restaurativos. Sobre a natureza dos dados tratados, a maioria se referia à agressão física - 53 - e ofensa - 46. (MELO; EDNIR; YAZBEK, 2008).

O projeto baseou-se na parceria entre Justiça e Educação, para construção de espaços de resolução de conflito e de sinergia de ação, em âmbito escolar, comunitário e forense. 
Mais tarde, o projeto foi ampliado para outras escolas estaduais no bairro de Heliópolis - SP - e na cidade de Guarulhos - SP, com apoio da Secretaria de Estado da Educação de São Paulo e das respectivas varas da infância e da juventude.

Abaixo a conclusão trazida pelo Juiz da Capital Paulista, Egberto Penido:

Foi possível atestar que a parceria Justiça e Educação representa significativo avanço na abordagem da questão da violência nas escolas, da escola e contra a escola. Constata-se que as escolas são espaços onde a implementação da Justiça Restaurativa se mostra não apenas de fundamental necessidade e urgência, mas, estrategicamente, como espaços de máxima eficácia na construção de uma efetiva Cultura de Paz. (PENIDO, 2008, p. 9).

As práticas restaurativas vêm ganhando espaço no cenário nacional, a partir de bons resultados obtidos com as experiências pioneiras mencionadas acima. Podemos concluir que, as medidas restaurativas principalmente no âmbito infanto-juvenil são de máxima relevância, endossando a ideia de que a cooperação Escola-Judiciário anda paralelamente, com a finalidade de mudar a realidade de uma sociedade conflituosa. Logo, não podemos ter a deficiência de abandono escolar, pois se trata de campo propício para o desenvolvimento dos círculos restaurativos.

A aplicação de medidas socioeducativas é operada de acordo com as características do ato infracional, salientando que para o Estatuto da Criança e do Adolescente ato infracional é a conduta descrita como crime ou contravenção penal.

Abaixo conceito de crime e contravenção penal sob a ótica do doutrinador Rosa: Sendo o conceito primordialmente normativo, crime pode ser compreendido como o que o direito vigente definir como tal, ou seja, será uma conduta proibida por lei, com previsão de pena. Resumidamente, pode-se entender a contravenção como infração penal de menor gravidade ou nas palavras do saudoso Ministro Nelson Hungria, "trata-se de crime anão". (ROSA, 2019, p. 64).

O procedimento de apuração de ato infracional deve ser revestido das garantias processuais próprias do direito penal e processual penal, e de todas as demais garantias e direitos atribuídos aos seres humanos e específicos da infância, pois o objetivo final não é a aplicação de uma "pena", mas sim, a proteção integral do adolescente.

Segundo Rosa:

As medidas socioeducativas, por isso, têm um caráter preponderantemente pedagógico, onde o intuito final e primordial deve ser a educação, inserção ou reinserção social, evitando-se a reincidência, inclusive, com a proteção ao adolescente egresso. (ROSA, 2019, p. 69 - grifo nosso).

Apesar de o ECA fazer analogia de crime e contravenção para definir o ato infracional e a sua apuração, ele possui a preocupação em se afastar das demais características penais do Código Penal, Processual Penal e da Lei de Execuções Penais. 
As medidas socioeducativas, serão operacionalizadas ainda, mediante as circunstâncias e disponibilidade de programas e serviços em nível municipal, regional e estadual.

Nesse contexto, Volpi ensina:

\begin{abstract}
As medidas socioeducativas comportam aspectos de natureza coercitiva, uma vez que são punitivas aos infratores, e aspectos educativos no sentido da proteção integral e oportunização, e do acesso à formação e informação. Sendo que em cada medida esses elementos apresentam graduação de acordo com a gravidade do delito cometido e/ou sua reintegração. (VOLPI, 2015, p. 25 - grifo nosso).
\end{abstract}

Todos os regimes socioeducativos, devem basear-se em pilares que garantam o acesso do adolescente a oportunidades de superação da sua condição de exclusão, e também acesso à formação de valores positivos.

O manuseio das medidas, devem obrigatoriamente conter envolvimento familiar e de membros da comunidade. Estes últimos contribuirão com as atividades e participarão ativamente no planejamento e controle das ações desenvolvidas na unidade de trabalho, estreitando, portanto, a relação entre o interno e a comunidade.

Em relação aos programas socioeducativos, Volpi afirma:

Os programas socioeducativos deverão utilizar-se do princípio da incompletude institucional, caracterizado pela utilização do máximo possível de serviços (saúde, educação, defesa jurídica, trabalho, profissionalização etc.) na comunidade, responsabilizando as políticas setoriais no atendimento aos adolescentes. Os programas socioeducativos de privação de liberdade deverão prever os aspectos de segurança, na perspectiva de proteção à vida dos adolescentes e dos trabalhadores, atentando-se para os aspectos arquitetônicos das instalações e formas de contenção sem violência. (VOLPI, 2015, p. 26 - grifo nosso).

Neste contexto, houve a descentralização do atendimento, a partir da Teoria da Proteção Integral adotada pelo ECA, dando ênfase à implementação das políticas públicas intersetoriais.

Além das garantias já elencadas, aos adolescentes que estiverem submetidos a medidas socioeducativas por algum ato infracional cometido, será assegurado tratamento digno, sem etiquetamentos.

Assim dispõe o doutrinador Volpi:

As denominações das unidades de aplicação das medidas, dos adolescentes envolvidos e das demais formas de identificação das atividades a eles relacionadas devem respeitar o princípio da não discriminação e não estigmatização, evitando-se os rótulos que marcam os adolescentes e os expõem a situações vexatórias, impedindo-os de superar suas dificuldades na inclusão social. (VOLPI, 2015, p. 26-27- grifo nosso). 
As medidas socioeducativas serão aplicáveis aos inimputáveis (menores de 18 anos) que cometerem qualquer ato infracional, de acordo com o artigo 104, do Estatuto da Criança e do Adolescente.

Importante fazer a distinção de atos infracionais cometidos por crianças (até 12 anos de idade), pois nestes casos serão aplicadas as medidas de proteção conforme dispõe artigo 105, do ECA, sendo o Conselho Tutelar o órgão competente por atender e aplicar tais medidas; e na sua ausência, suas atribuições serão atendidas pela autoridade judiciária (juiz da infância e juventude).

As medidas de proteção previstas no artigo 101 do ECA, são: I - encaminhamento aos pais ou responsável, mediante termo de responsabilidade; II - orientação, apoio e acompanhamento temporários; III - matrícula e frequência obrigatórias em estabelecimento oficial de ensino fundamental; IV - inclusão em serviços e programas oficiais ou comunitários de proteção, apoio e promoção da família, da criança e do adolescente; $\mathrm{V}$ - requisição de tratamento médico, psicológico ou psiquiátrico, em regime hospitalar ou ambulatorial; VI - inclusão em programa oficial ou comunitário de auxílio, orientação e tratamento a alcoólatras e toxicômanos; VII - acolhimento institucional; VIII - inclusão em programa de acolhimento familiar; IX - colocação em família substituta.

Já nos atos infracionais cometidos por adolescentes (maiores 12 e menores de 18 anos de idade), serão cabíveis as medidas socioeducativas ilustradas abaixo, de acordo com o artigo 112 do Estatuto da Criança e do Adolescente:

\section{Figura 1: Medidas socioeducativas- ECA.}

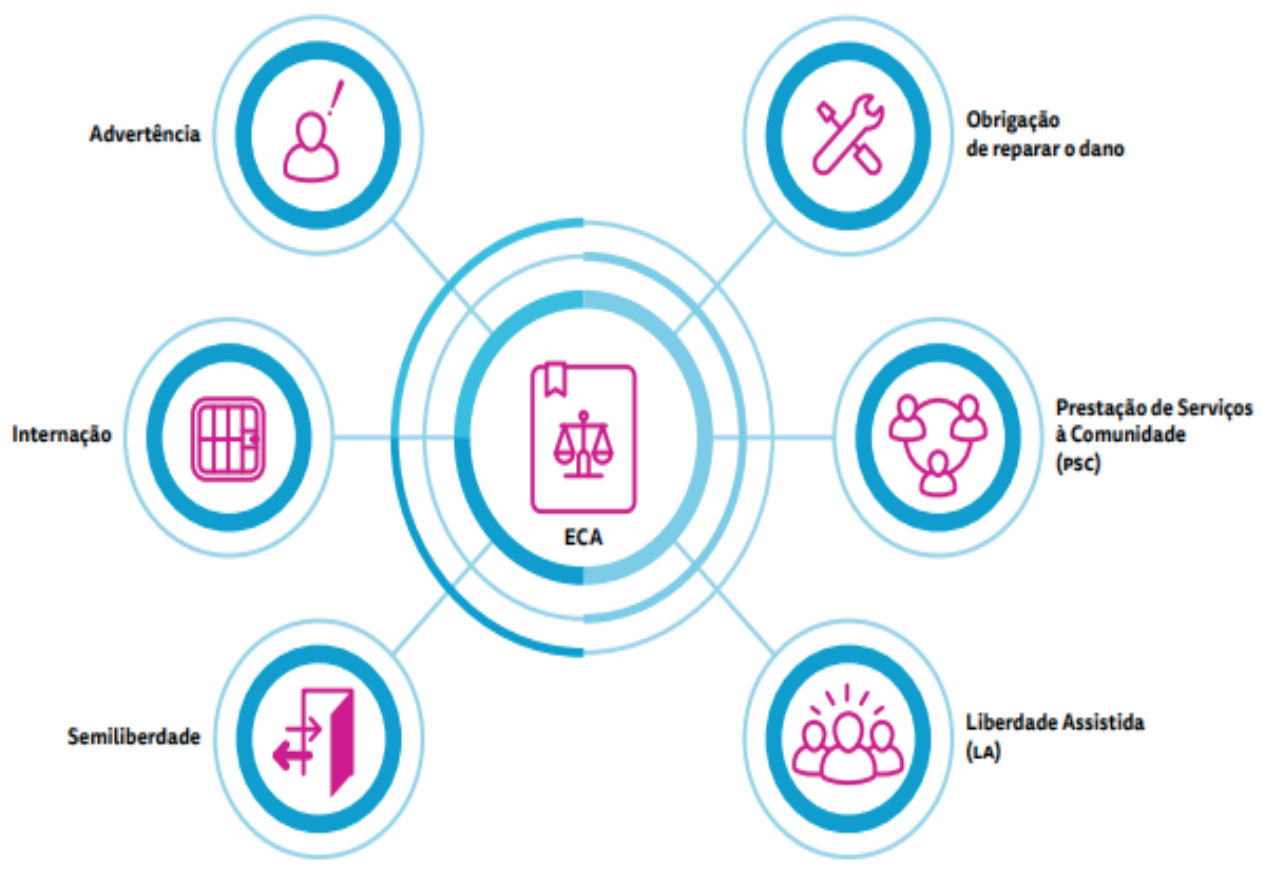

Fonte: INSTITUTO SOU DA PAZ (2018). 
Estes atos infracionais, serão apurados pela Delegacia da Criança e do Adolescente, e deverão ser encaminhados ao Juiz da Infância e Juventude, conforme veremos mais adiante.

A advertência constitui uma medida informativa, imediata, por meio de uma repreensão verbal ao adolescente, executada pelo Juiz.

Silva (2008, p. 51) alega que "não autoriza a sua aplicação quando não provada a autoria e a materialidade do ato infracional, não havendo de se falar em advertência preventiva em caso de dúvida".

Ela será aplicável, quando o ato infracional for considerado de menor gravidade, não afastando seu caráter intimidador, pois a advertência será reduzida a termo e assinada pelas partes.

Portanto, a advertência produz efeitos jurídicos e passa a constar no registro de "antecedentes" do adolescente, podendo ainda, colaborar de maneira decisiva na escolha de uma nova medida socioeducativa, no caso de novas infrações.

A medida socioeducativa de reparação do dano, será imposta, quando o ato infracional praticado pelo adolescente ocasionar prejuízos materiais, logo devendo ser reconhecido e reparado desde que o adolescente detenha condições para tanto.

Assim dispõe Volpi:

A reparação do dano se faz a partir da restituição do bem, do ressarcimento e /ou da compensação da vítima. Caracteriza-se como uma medida coercitiva e educativa, levando o adolescente a reconhecer o erro e repará-lo. A responsabilidade pela reparação do dano é do adolescente, sendo intransferível e personalíssima. (VOLPI, 2015, p. 28 - grifo nosso).

Alguns autores compreendem que esta medida deveria ser aplicada em paralelo ao Código Civil Brasileiro, pois neste último, nos casos de adolescentes menores de 16 anos, a responsabilidade de reparar o prejuízo causado recai sobre seus pais ou responsáveis, e para os casos de adolescentes maiores de 16 anos e menores de 18 anos, a responsabilidade é solidária entre pais e adolescente.

Contudo o que prevalece, é que o adolescente possui responsabilidade personalíssima de reparação, e nos casos que não tiverem condições econômicas, a autoridade poderá substituir esta medida, por outra mais adequada.

A prestação de serviços à comunidade (PSC) possui duração máxima de 6 meses e é dotada de forte apelo comunitário e educativo para o jovem infrator e para a comunidade, que por sua vez será responsável pelo desenvolvimento integral desse adolescente.

Abaixo Volpi disserta quanto à sua efetividade:

Entendemos que a prestação de serviços à comunidade será cada vez mais efetiva na medida em que houver o adequado acompanhamento do adolescente pelo órgão executor, o apoio da entidade que o recebe, e a utilidade real da dimensão social do trabalho realizado. (VOLPI, 2015, p. 29). 
Essa medida socioeducativa para o jovem, será uma oportunidade de ter a experiência da vida comunitária, valores sociais e compromisso.

A liberdade assistida (LA) constitui-se em uma medida coercitiva quando se constata necessidade de acompanhamento na vida social do adolescente (escola, trabalho e família). Ela possui durabilidade de no mínimo 6 meses, comparecendo o adolescente na instituição em dias preestabelecidos para seu atendimento.

Sua finalidade é impedir que o adolescente cometa novos atos infracionais, a partir das orientações dadas pelo agente que o acompanha.

Dessa forma assevera Volpi:

Sua intervenção educativa manifesta-se no acompanhamento personalizado, garantindo-se os aspectos de: proteção, inserção comunitária, cotidiano, manutenção de vínculos familiares, frequência à escola, e inserção no mercado de trabalho e ou cursos profissionalizantes e formativos. Assim, os programas de liberdade assistida devem ser estruturados no nível municipal, preferencialmente localizados nas comunidades de origem do adolescente. Devem ainda, ser gerenciados e desenvolvidos pelo órgão executor no nível municipal em parceria com o judiciário, que supervisiona e acompanha as ações do programa. (VOLPI, 2015, p. 30- grifo nosso).

Logo, a modalidade de liberdade assistida tem se mostrado muito eficaz pelo grau de envolvimento na comunidade e de inserção no cotidiano dos adolescentes acompanhados.

A semiliberdade consiste em medida socioeducativa restritiva. Se trata de medida coercitiva, pois afasta o adolescente do convívio familiar e da comunidade de origem.

Contudo, essa restrição de liberdade não o priva totalmente de seu direito de ir e vir, é um intermediário entre privação e regime semiaberto, suprimindo alguns direitos, possibilitando, sobretudo, que o adolescente realize atividades em ambiente externo.

É elaborado um plano para o adolescente de maneira individual, que deverá ser executado pelas instituições. Sendo dever do órgão competente, além de realizar atividades educacionais e profissionalizantes, oferecer comida e abrigo, pois os mesmos residem em seu espaço.

Tal medida não possui um prazo específico de duração, mas este deve obrigatoriamente ser revisto a cada 6 meses pela equipe interdisciplinar da instituição.

Os programas de semiliberdade devem manter ampla relação com serviços e programas sociais no âmbito externo à unidade de moradia.

Volpi ensina:

Num entendimento mais amplo da natureza e finalidade da semiliberdade, entendemos que ela é capaz de substituir em grande parte a medida de internação, podendo atender os adolescentes como primeira medida, ou como processo de transição entre a internação e o retorno do adolescente a comunidade. (VOLPI, 2015, p. 32). 
A medida de semiliberdade é aplicável a atos infracionais, que sejam classificados como crime de médio e alto potencial ofensivo, desde que sejam observadas a realidade social do adolescente, bem como sua condição pessoal, para que a medida mais eficaz seja aplicada ao caso concreto.

A última das medidas será a internação, funcionando de maneira hierárquica que vai da menos grave para a mais grave. Essa será direcionada aos adolescentes que cometerem atos infracionais graves. Segundo Volpi (2015, p. 34), “Embora o Estatuto tenha enfatizado os aspectos pedagógicos e não os punitivos ou repressivos, a medida de internação guarda em si conotações coercitivas e educativas".

O Estatuto em seu artigo 122, parágrafo $2^{\circ}$, estabelece o princípio que todo adolescente a quem for imputada uma medida socioeducativa não deverá ser privado de sua liberdade se houver outra medida cabível.

Portanto, a internação significa um programa de privação de liberdade, a qual implica na contenção do adolescente autor de ato infracional, em um sistema de segurança.

De acordo com Volpi:

Assim sendo, os que forem submetidos à privação de liberdade só o serão porque a sua contenção e submissão a um sistema de segurança são condições sine qua non para o cumprimento da medida socioeducativa. Ou seja, a contenção não é em si a medida socioeducativa, é a condição para que ela seja aplicada. De outro modo ainda: a restrição da liberdade deve significar apenas limitação do exercício pleno do direito de ir e vir e não de outros direitos constitucionais, condição para sua inclusão na perspectiva cidadã. (VOLPI, 2015, p. 35 - grifo nosso).

Os infratores contidos terão suas garantias constitucionais asseguradas. Tais quais:

Sujeição aos princípios de brevidade, excepcionalidade e respeito à condição peculiar de pessoa em desenvolvimento; manutenção condicionada à avaliação em períodos máximos de seis meses; tempo máximo de internação de três anos, limite após o qual o adolescente deve ser liberado e colocado em regime de semiliberdade ou de liberdade assistida; e liberação compulsória aos vinte e um anos de idade (art.121); permissão para realização de atividades externas, a critério da equipe técnica da entidade, salvo expressa determinação judicial em contrário (art.121, parágrafo $1^{\circ}$ ); que a internação seja cumprida em entidade exclusiva para adolescentes, obedecida rigorosa separação por critérios de idade, compleição física e gravidade da infração. Durante esse período (inclusive na internação provisória), são obrigatórias atividades pedagógicas (art. 123); observação dos direitos do adolescente privado de liberdade [...]. (VOLPI, 2015, p. 35 e 36- grifo nosso).

Importante destacar que, em nenhuma hipótese os jovens submetidos à internação ficarão incomunicáveis, embora o poder judiciário possa suspender temporariamente as visitas ao adolescente.

O período de internação será de no mínimo 6 meses e máximo de 3 anos (após o adolescente completar 21 anos, o mesmo deverá ser liberado compulsoriamente). 
Obrigatoriamente a equipe do centro de internação deve preparar relatórios semestrais dedicados ao comportamento do adolescente, para que então o juiz possa tomar decisão de progredir regime ou conceder a liberação da medida.

\section{DA CRIMINOLOGIA AO PREJULGAMENTO INFANTO-JUVENIL}

A criminologia é um convite para a investigação ampla do crime (criminogênese), bem como a interação entre o criminoso, a vítima e o controle social. Não se analisa, então, o fato criminoso isoladamente, mas sim o conjunto.

Para um estudo completo do crime, exige-se uma análise ampla, mais de uma forma de abordagem - desse modo é possível falar em estudo interdisciplinar, uma vez que psicólogos, psiquiatras, sociólogos, pedagogos, antropólogos e juristas se debruçam sobre o tema.

O doutrinador Salo de Carvalho, em sua obra "Antimanual de Criminologia", coloca que o grande desafio da Criminologia está na sua abertura para diálogo com outras fontes do saber, sobremaneira que o objetivo não seria criar modelos integrados de ciências criminais, mas, sim, modelos de integração de diferentes ramos. (CARVALHO, 2008).

Neste sentido, Trindade explica:

Num primeiro momento pode parecer estranho, em se tratando de delinquência juvenil, a remissão à criminologia. Mas, sucede que o problema relativo à aplicação da delinquência juvenil, de início, coloca-se do mesmo modo como se propõe a questão geral da criminologia. (TRINDADE, 1996, p. 80).

Outro ponto importante que se faz necessário é uma visão que vá além da aplicação da lei a um fato já ocorrido, de modo tardio e no sentido de reparação. O olhar da criminologia por sua vez, estuda o que precede o comportamento criminoso.

Uma das maiores vantagens do estudo criminológico, é que este estuda o porquê dos crimes, e essa é uma das maiores preocupações da modernidade, pois as desigualdades sociais, a violência, dentre outros fatores, têm causado perplexidade, acompanhada de descrença preventiva e restaurativa, medo, ódio social com carga muitas vezes preconceituosa.

O doutrinador Shecaira diz que:

Criminologia é um nome genérico designado a um grupo de temas estreitamente ligados: o estudo e a explicação da infração penal; os meios formais e informais de que a sociedade se utiliza para lidar com o crime e com atos desviantes; a natureza das posturas com que as vítimas desses crimes serão atendidas pela sociedade; e, por derradeiro, o enfoque sobre o autor desses fatos desviantes. (SHECAIRA, 2004, p. 31).

No campo científico ainda existe a discussão segundo a qual as ciências humanas, não seriam de fato ciências, por não serem dotadas de teorias de validade universal, ou métodos unitários e específicos. Sobretudo, Shecaira (2004, p. 37) 
afirma que como qualquer ciência humana (a criminologia) apresenta um conhecimento parcial, fragmentado, provisório, fluído, adaptável à realidade e compatível com as evoluções históricas e sociais". Importante salientar que, majoritariamente a criminologia é considerada ciência.

Portanto, para se entender a criminologia e sua relevância no prejulgamento infanto-juvenil, se faz necessário frisar que o crime é um fenômeno que é ao mesmo tempo individual e social. Logo, sendo um fenômeno comunitário deve ser encarado como um problema social.

A delinquência juvenil é complexa e composta por diversos fatores que influenciam no comportamento desviante de um jovem, existindo, contudo, várias teorias para a origem da criminalidade, cada uma se aplicando para definir esta ou aquela situação, mas nenhuma irá definir o berço de todos os delitos, visto que não há uma teoria geral da criminalidade, sendo os crimes distintos e variadas as motivações.

Dentre as teorias de comportamento delinquente, uma das que se enquadra de modo geral ao cenário de infração juvenil brasileira, é a Teoria da Anomia, também chamada de Teoria Estrutural Funcionalista, desenvolvida por Robert King Merton (1938).

Entende-se que Teoria da Anomia é uma situação social que surge pela ausência da ordem, normas e valores sociais, sendo considerada uma teoria do consenso. Essa teoria atinge dois primas conflitantes entre si, sendo metas culturais (status, riqueza, poder) e os meios institucionalizados (escola, trabalho, igreja, família).

Segundo a Teoria da Anomia, existem objetivos sociais e culturais que a sociedade estabelece como referências para uma vida bem-sucedida. O sucesso econômico é um dos principais objetivos almejados pela sociedade, em conjunto com os meios moralmente aceitáveis para se perseguir tais objetivos.

Quando o indivíduo assimila os objetivos sociais, porém não possui os meios para alcançá-los, acaba ocorrendo os desvios comportamentais. É de se dizer que a sociedade impõe objetivos a serem almejados, sem minimamente prover oportunidades igualitárias para alcançá-los, impulsionando as crianças e os adolescentes a encontrarem meios desviantes para atingir o status social.

Devemos emergir no que tange aos meios necessários para atingir as metas estipuladas pela sociedade, fazendo-se necessário observar onde está o gap, que gera desigualdades latentes e consequentemente, desvios infanto-juvenis.

O pensamento utópico teve como precursor Thomas More (1478-1535), um dos primeiros a ressaltar a conexão de crime com os fatores socioeconômicos, com a estrutura da sociedade. Para Thomas More, o crime responde a uma pluralidade de fatores, tais como, guerra, déficit cultural e educativo, o ambiente social, ociosidade, dentre outros. Mas, entre eles, se destacam os socioeconômicos, desigual distribuição de riqueza. (MOLINA, 2003).

Nessa mesma linha de raciocínio, Jean Jacques Rousseau (1712-1778) acredita que o crime surge com o contrato social. Em sua obra "O contrato social” (1762), ele formula o argumento de que o homem é naturalmente bom, sendo que a socie- 
dade o perverte. Em seu entendimento, o crime demonstraria a má estruturação do pacto social, a desorganização do Estado.

No ponto de vista de Calhau, a deterioração dos grupos primários (ex. família), a modificação qualitativa das relações interpessoais que se tornam superficiais, a alta mobilidade, perda de raízes no lugar de residência, a crise dos valores tradicionais e familiares, a superpopulação, a tentadora proximidade às áreas comerciais e industriais, onde se acumula riqueza, e o referido enfraquecimento do controle social criam um meio desorganizado e criminógeno. (CALHAU, 2009).

De acordo com Vieira (1999, apud GOUDINHO, [20-?], p. 3), "os motivos que levam o adolescente a cometer atos infracionais vão desde a influência de amigos, uso de drogas, evasão escolar, até a pobreza". Tal situação demostra a vulnerabilidade da criança e do adolescente à influência de terceiros.

Observamos, por conseguinte, que as causas da criminalidade e da violência entre jovens estão ligadas a diferentes fatores, tais como: inserção em determinados grupos, desestruturação familiar (associados com abuso ou negligência parental), desigualdades socioeconômicas, drogadição, abandono escolar, desprovimento de lazer, cultura, diversão, religião, residência em periferias (ambientes geralmente instáveis), entre outros.

Segundo Rosa:

O caminho de um adolescente até o ato infracional é marcado, na grande maioria das vezes, por histórico de desorganização familiar, baixa escolaridade, omissão do Poder Público nos direitos básicos, consumo e envolvimento com drogas além de outros fatores ligados ao próprio desenvolvimento de sua personalidade. (ROSA, 2019, p. 53).

Logo, os fatores externos são grandes influenciadores na formação da criança e do adolescente, de tal maneira que acabam se tornando determinantes na ocorrência de delitos cometidos por estes.

Para a teoria ecológica da Escola de Chicago, as cidades possuem o fenômeno criminal, sendo a cidade nociva e produtora de delinquência. Existem ainda, áreas bastantes definidas, onde a criminalidade se concentra, e outras em que seria bastante reduzida. Entende-se que, o ambiente exerce influência sobre o indivíduo. (CALHAU, 2009).

Para a elucidação do presente tema, importante trazer uma pesquisa realizada em 2017 pelo Instituto Sou da Paz, que constata que 67,7\% dos adolescentes infratores internados na Fundação Casa não frequentavam escola na época em que foram detidos. De acordo com os dados, $37,5 \%$ dos adolescentes estavam matriculados, mas não frequentavam as aulas antes da internação atual. Outros 30,2\% não estavam matriculados e nem frequentavam as aulas, e 32,3\% estavam matriculados e frequentavam as aulas. 


\section{Figura 2: Situação escolar antes da internação atual.}

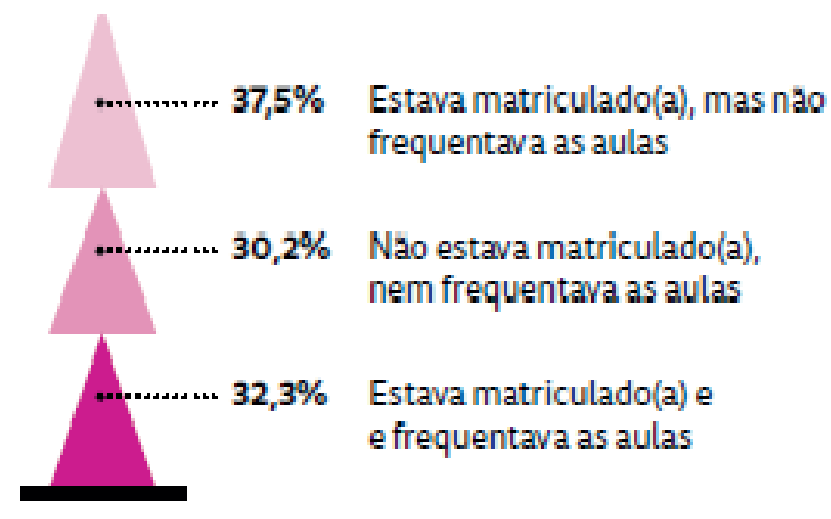

Fonte: INSTITUTO SOU DA PAZ (2018).

Neste mesmo sentido, uma pesquisa realizada no ano de 1996 aponta que 61,2\% dos adolescentes não frequentavam a escola na época da prática do ato infracional:

A grande maioria dos adolescentes pesquisados - 96,6\% - não concluiu o ensino fundamental. A porcentagem de analfabetos é de $15,4 \%$. O número de adolescentes que concluíram o $2^{\circ}$ grau, consequentemente (sic), torna-se praticamente nulo - 7 num total de 4.245 (cujas informações foram obtidas), o que representa a ínfima parcela de $0,1 \%$ [...] dos 4.245 adolescentes, sujeitos desta pesquisa, $2.498-61,2 \%$, portanto - não frequentavam (sic) a escola por ocasião da prática do ato infracional. (VOLPI, 2015, p. 73 e 74).

Observa-se claramente que em vinte e um anos, o que já era um problema, apenas se agravou, e a ausência de pilares básicos consequentemente se reflete na delinquência infanto-juvenil.

Neste contexto, quando um jovem se desvia, e comete um delito é visto como um marginal. Além disso, ele é tachado, e cria-se um estereótipo desse jovem, com discurso de indivíduo marginalizado socialmente, morador de comunidade, não alfabetizado, sem estrutura familiar, pobre, já diagnosticado como um problema potencial a ser corrigido. (BORGES, 2013).

Nesse mesmo sentido Volpi ensina:

Não existe ainda um consenso geral sobre como denominar os adolescentes que praticam atos infracionais. Os meios de comunicação social, em geral, têm preferido usar formas estigmatizantes, referindo-se a eles como infratores, delinquentes, pivetes e, mais recentemente, importando uma expressão dos EUA, uma revista semanal taxou-os de "pequenos predadores". A opinião pública em geral tem reproduzido estas expressões, acrescentando outras que a sua criatividade preconceituosa produz como: bandidos, trombadinhas, menores infratores e outras. Entre os profissionais que atuam na área há ainda os que se 
expressam de maneira preconceituosa, entretanto, um grupo cada vez maior, busca a sua caracterização a partir do que eles realmente são: adolescentes. A prática do ato infracional não é incorporada como inerente à sua identidade, mas vista como uma circunstância de vida que pode ser modificada. (VOLPI, 2015, p. 9 e 10 - grifo nosso).

Além da criança e do adolescente que cometem o ato infracional, são colocados na mesma "caixa" aqueles que possuem perfil semelhante, ainda que não tenham cometido nenhum delito.

Meninos e meninas ainda são chamados de "menores", termo este discriminatório, que marcou (e marca), desde o século XIX as crianças pobres e negras, desemparadas ou delinquentes, como sendo portadores de essência negativa, que determinaria e explicaria seus comportamentos desviantes. Ainda hoje tais adolescentes são em geral vistos com olhar de desconfiança pelo senso comum, pela mídia e pela Justiça, quer tenham cometido atos infracionais ou não. (PAIVA; SOUZA; RODRIGUES, 2014).

Notória é a existência do prejulgamento acerca de determinados grupos, em detrimento de rótulos criados. Adolescentes pobres, em geral, notam tratamento hostil da polícia, que generaliza e vê todos como possíveis suspeitos e criminosos. Essa força de repressão do Estado, da polícia, é muito utilizada pelo poder público, para controle desse grupo da população mais vulnerável, composto pelos jovens da periferia, estereotipados e rotulados, como "prováveis bandidos". (BORGES, 2013).

A teoria crítica da criminologia sustenta que descendentes da classe pobre são investigadas, enquanto que, na classe alta isso não ocorre. Tal entendimento nasce da ideia de que exista seletividade por parte do controle social para com os crimes cometidos e seus autores. Resta cristalina a violação dos direitos constitucionais da presunção de inocência e da dignidade da pessoa humana. (ALBUQUERQUE, 2018).

Essa perspectiva nos remete à Teoria do Labelling Approach, que surgiu nos Estados Unidos em torno dos anos 1970, possuindo outras nomenclaturas, tais como: teoria da rotulação, teoria interacionista, teoria da reação social, entre outras. Essa teoria, visa analisar como se dá a rotulação em torno de determinadas pessoas, quem rotula e quem é rotulado, bem como isso interfere e reflete na dinâmica econômica de um determinado grupo, diferenciando os detentores do capital do proletariado.

A teoria do etiquetamento, sustenta que as noções de crime e criminoso são construídas socialmente a partir de uma definição imputada ao sujeito, uma espécie de etiqueta, rótulo como delinquente ou não. (ALBUQUERQUE, 2018).

Neste sentido, insere-se o conceito de seletividade penal tipificando comportamentos - isso porque etiquetar uma determinada conduta para que seja tratada como criminosa implica rotular e etiquetar indivíduos, logo, definindo contra quais indivíduos recairá o aparato punitivo.

Assim, o problema que se encontra é que há uma transparente ineficiência do Estado no equilíbrio social e, por consequência, um prejulgamento antecipado da sociedade em torno da juventude brasileira. Noutras palavras, uma rotulação de 
determinados grupos, o que viabiliza factualmente de forma contínua condenações equivocadas.

Necessário parafrasear o famoso 'caso' "The Central Park Five", que, por sua vez, diz respeito ao estupro ocorrido em 19/04/1989 no Central Park (Nova Iorque), onde foi imputado o crime a cinco adolescentes - injustamente, sem nenhuma prova.

Essa condenação antecipada ocorreu em detrimento de etnia e classe social (negros, latinos e pobres). Na época dos fatos a cidade estava imersa numa epidemia de crack e assombrada por gangues e o Estado e a sociedade clamavam por justiça. Assim, e em razão de rótulos, etiquetas, "caixas", acabou-se atribuindo o crime a quem não o cometeu, sem a devida observância aos princípios da dignidade da pessoa humana, presunção de inocência e in dubio pro réu.

Desta feita, considerando as abordagens dos autores citados e até mesmo a analogia feita com um caso concreto, fato é que não podemos ignorar a assistência que toda criança e adolescente precisam, devem e merecem ter. A participação ativa da família, Estado e sociedade é fator contributivo determinante no (bom) desenvolvimento da criança e do adolescente.

É impreterível que cada caso concreto seja observado na sua singularidade, sem realizar juízos prévios, a fim de não condenar e rotular indevidamente aqueles que não cometeram nenhum desvio.

\section{DA FUNDAÇÃO CASA À RESSOCIALIZAÇÃO}

A Fundação Centro de Atendimento Socioeducativo ao Adolescente (Casa), é vinculada à Secretaria de Estado da Justiça e da Defesa da Cidadania, cuja missão é de aplicar em todo o estado de São Paulo as medidas socioeducativas de privação de liberdade (internação) e semiliberdade ao adolescente que tenha praticado algum ato infracional.

Possuindo mais de 150 unidades distribuídas pelo estado, a Fundação Casa em 2005 iniciou o programa de descentralização do atendimento, implantando até 2015, um total de 72 pequenos novos centros socioeducativos em todo estado, com capacidade para atender até 64 jovens.

A proposta deste modelo é promover a queda nas taxas de reincidência dos adolescentes e diminuir eventuais rebeliões. Esse modelo almeja ainda, aprimorar a qualidade no atendimento, haja vista que o adolescente será atendido próximo de sua família e de preferência dentro de sua comunidade, com maior atenção dos profissionais, facilitando, portanto, a reinserção social.

A Fundação Casa executará na prática as medidas mais gravosas, sendo estas o último recurso para os atos infracionais cometidos pelos adolescentes. Sua carga é coercitiva e principalmente educativa, para que assim possibilite a verdadeira reabilitação.

Portanto, precisamos analisar se na prática a teoria se concretiza, se os mecanismos despendidos alcançam sua finalidade de reformar o adolescente e prepará-lo para uma nova vida, pautada em pilares sólidos, longe da criminalidade. 
Para isso, o objetivo em comum dos profissionais da Fundação Casa, deve ser de expandir os horizontes dos adolescentes internados e conscientizá-los sobre a existência de outras chances, incluindo aquelas ligadas à cultura e ao lazer. Esses profissionais devem mostrar aos adolescentes que é possível levar uma vida digna por meio do trabalho, por isso, é necessário que detenham clareza em relação ao caráter pedagógico da medida.

O Instituto Sou da Paz, entre 2016 e 2017, realizou uma pesquisa valiosa acerca dos adolescentes em conflito com a lei no estado de São Paulo, com foco na Fundação Casa. Entre os entrevistados estavam os jovens que cumpriam medida socioeducativa, e também, seus colaboradores ${ }^{1}$.

Um dos resultados obtidos foi quanto aos profissionais da Fundação Casa, que expressaram receio sobre a falta de um olhar sistêmico da rede de atendimento aos adolescentes, bem como sobre as dificuldades de acesso a serviços públicos pelos egressos em seus territórios de origem e o diálogo limitado entre os responsáveis pela execução das medidas socioeducativas em meio aberto e fechado. Muitos internos retornam às suas casas com maior afastamento da vivência familiar e comunitária, profundamente estigmatizados e sem apoio para a reinserção escolar (dificuldades em se matricular e/ou discriminação por parte de colegas e professores) e para a obtenção de empregos.

Além disso, foram realizadas repetidas críticas dos profissionais às condições precárias de trabalho em alguns centros socioeducativos, sobretudo quanto ao subdimensionamento das equipes e à falta de oportunidades para a capacitação profissional, ponto este que merece atenção, visto que os profissionais não atingirão o objetivo sem as condições necessárias?).

A escassez de profissionais e ausência de apoio técnico tornam exaustivas as tarefas dos servidores da área e prejudicam a construção de vínculos com os adolescentes. É fundamental investir no quadro de funcionários para garantir um atendimento individualizado por técnicos e agentes bem formados, pautados nos princípios e valores do ECA.

Por outro lado, a pesquisa também serviu de termômetro quanto à percepção dos adolescentes internados e muitos demonstraram satisfação com a educação formal oferecida pela Fundação Casa, considerando que ela é capaz de despertar o interesse pela escola, que antes estava adormecido. Muitos internos, afirmaram engajamento nos estudos durante o cumprimento da medida, pois o diferencial são turmas menores e atenção maior dos professores.

Já em relação aos cursos profissionalizantes, praticamente metade dos adolescentes entrevistados afirmou que não pretende exercer atividades ligadas aos cursos oferecidos. Prefeririam cursos de caráter prático e que os introduzissem no mercado de trabalho.

1 Vários trechos da entrevista foram utilizados como base para a elaboração deste capítulo nos parágrafos que se seguem a este. Ela pode ser lida, na íntegra, em: http://www.mpsp.mp.br/ portal/page/portal/documentacao_e_divulgacao/doc_biblioteca/bibli_servicos_produtos/BibliotecaDigital/BibDigitalLivros/TodosOsLivros/ai_eu_voltei_pro_corre_2018.pdf 
Grande parte dos adolescentes demonstrou pouco conhecimento quanto ao Plano Individual de Atendimento (PIA) que possui previsão expressa no Estatuto da Criança e do Adolescente. Para muitos internos, não há transparência sobre os objetivos da medida socioeducativa e como ela pode agregar em suas vidas. Muitos enxergam as atividades oferecidas como ferramenta que apenas compõe relatórios encaminhados ao Judiciário, como se fosse uma etapa para alcançarem a liberdade.

$\mathrm{O}$ atendimento psicossocial foi bastante criticado por boa parte dos entrevistados, pois é pouco frequente, além de ser repetitivo e inclinado somente aos atos infracionais praticados. Isso foi constatado, pois os internados pareciam habituados a falar sobre os seus atos infracionais e dificilmente falavam sobre suas famílias, amigos, planos para o futuro e sentimentos.

Outro ponto que ficou evidenciado pela pesquisa, foi a elevada quantidade de depoimentos de violência por parte de servidores da Fundação Casa. Um quarto dos internados entrevistados relatou agressões físicas pelos agentes, o que acaba violando direitos e comprometendo o caráter pedagógico da medida socioeducativa.

Dessa maneira, os pontos frágeis no atendimento socioeducativo em internação revelados pela pesquisa foram: condições precárias de trabalho em determinados centros socioeducativos; articulação limitada entre profissionais da Fundação Casa e atores da rede de proteção do adolescente; baixa individualização da medida socioeducativa de internação; educação profissional pouco alinhada aos interesses do adolescente; atendimento psicossocial e vínculo frágil com a equipe de referência; violência física e verbal praticada por agentes socioeducativos em alguns centros.

Em relação ao perfil e aos atos infracionais cometidos pelos jovens que cumprem medidas socioeducativas em São Paulo, a pesquisa diz que a maior parte dos adolescentes que cumprem medida é preta ou parda (76\%), tem 16 ou 17 anos $(60 \%)$ e cometeu o primeiro ato infracional entre os 12 e 14 anos $(60 \%)$. O roubo e o tráfico de drogas perfizeram $80 \%$ dos atos infracionais cometidos pelos internos; apenas $8,93 \%$ cumpriam medida socioeducativa por atos infracionais equiparados a homicídio, latrocínio e estupro. Dois terços dos entrevistados já cumpriram outras medidas socioeducativas, incluindo internações anteriores na Fundação Casa, Semiliberdade, Liberdade Assistida ou Prestação de Serviços à Comunidade.

Ainda de acordo com a pesquisa, três quartos tinham familiares que estiveram ou estavam desempregados, 9 entre 10 entrevistados contaram episódios de agressões físicas cometidas por policiais militares, sobretudo durante abordagens e apreensões de drogas. Muitos descreveram constrangimentos e humilhações sofridas em seu cotidiano, seja na escola, em estabelecimentos comerciais ou em equipamentos públicos.

Também se confirma que o círculo de amigos e a busca de aceitação pelos companheiros, característicos da adolescência, são importantes mecanismos facilitadores da entrada no mundo infracional.

Os números expostos ressaltam o peso da vulnerabilidade socioeconômica e da exposição à violência entre os fatores de risco dos adolescentes internados 
em São Paulo. Contudo, a vulnerabilidade socioeconômica não justifica a conduta infracional, haja vista o grande contingente de jovens de baixo poder econômico que não se envolve em atos infracionais. Mas conclui-se que grande parte dos adolescentes internados na Fundação Casa e seus familiares é vulnerável, com acesso precário a serviços públicos, além de sofrer grande exposição à violência policial.

A taxa de reincidência após o cumprimento da medida socioeducativa em meio fechado e meio aberto é alarmante.

Abaixo, os dados da pesquisa:

Figura 3: Tabela de reincidência dos adolescentes entrevistados da Fundação Casa.

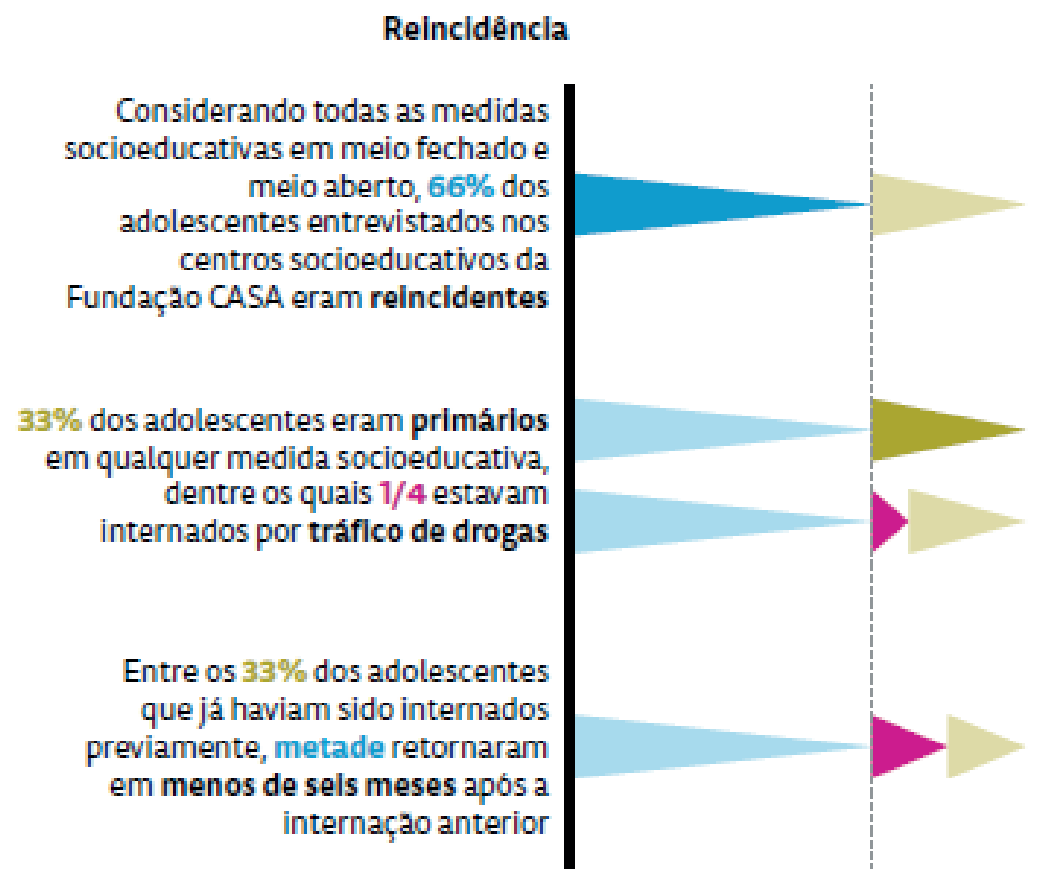

Fonte: INSTITUTO SOU DA PAZ (2018).

Notamos diante disso que, não basta o acompanhamento do jovem apenas durante o cumprimento da medida socioeducativa. Se faz necessário um acompanhamento pós-internação, além de assegurar que o trabalho iniciado na Fundação Casa seja contínuo, principalmente pelos 6 meses iniciais, considerados "críticos" na vida do adolescente.

A pesquisa do Instituto Sou da Paz, mostrou que as dificuldades encontradas após a internação são: perseguição policial $(47,4 \%)$, desemprego $(23,2 \%)$, dificuldades em integração escolar $(22,1 \%$, ) discriminação $(18,9 \%)$, dificuldades em acessar serviços $(6,3 \%)$, outros motivos $(9,0 \%)$. Apenas $22,1 \%$ relataram que não tiveram nenhuma dificuldade. 
Nesse sentido, evidente é que o acompanhamento do jovem que tenha cometido algum ato infracional transcende ao cumprimento da medida socioeducativa. A Fundação Casa não é o fim, e sim o meio, neste processo de reeducação, reconstrução, ressignificação de princípios e valores, sendo necessário a participação ativa da família, do Estado e da sociedade.

\section{CONSIDERAÇÕES FINAIS}

O desenvolvimento do presente estudo se debruçou preliminarmente sobre a evolução nos direitos da criança e do adolescente, que passaram de objetos pertencentes à propriedade de alguém (família ou Estado), até a fase atual de proteção integral e prioritária, sendo sujeitos de direitos em condição de crescimento e constante desenvolvimento.

Neste sentido, abordamos o Estatuto da Criança e do Adolescente - ECA, que surgiu para disciplinar os direitos fundamentais, estabelecendo inclusive, diferenciação entre criança e adolescente carente daqueles que tenham cometido algum ato infracional - substituindo, portanto, os arcaicos códigos anteriores que se utilizavam de terminologias pejorativas, tais como menor abandonado, delinquente e em situação irregular.

Passamos ainda, pela Justiça Restaurativa Brasileira, que é uma inovadora opção, pois retira totalmente o enfoque da justiça retributiva e busca a ressignificação de valores na vida pessoal e social dos jovens, sendo esta uma justiça participativa, que atua como sendo complementar à justiça comum. Funciona como uma possibilidade de conciliação entre as partes, de forma natural, sem que haja uma força coercitiva.

O estudo se dedicou, passando pela criminologia, a buscar as possíveis causas da prática do ato infracional, ou seja, porque crianças e adolescentes tendem a praticar crimes. E concluímos que, as principais causas, são desestruturação familiar, desigualdades socioeconômicas (pobreza em virtude de omissão do Poder Público nos direitos básicos), influência de amigos, drogadição.

Outras causas: evasão e abandono escolar, desprovimento de lazer, cultura, diversão, religião, residência em periferias (comunidades são ambientes geralmente instáveis), além de outros fatores ligados ao próprio desenvolvimento de sua personalidade.

Uma vez que o jovem se desvia, ele passa a ser visto na prática como um indivíduo marginalizado sem reparação, e é colocado na mesma caixa de outras crianças e adolescentes que possuem características similares, mesmo que não tenham cometido nenhum ato infracional.

Evidente é o preconceito que se vê em determinados grupos mais desfavorecidos. A sociedade e o próprio Estado suspeitam desses grupos, tratando-os com bastante hostilidade, generalizando todos como potenciais "bandidos". Assim procedendo, fazem com que surja seletividade no controle social para com os crimes e seus autores. Em algumas situações notamos investigação da classe rotu- 
lada, enquanto não há sequer desconfiança daqueles pertencentes à classe alta, o que viola, sobremaneira, princípios constitucionais da presunção de inocência e da dignidade da pessoa humana.

Para ilustração do estudo, trouxemos um caso concreto de condenação pautada em caráter discriminatório, o famoso caso The Central Park Five, que ocorreu em 1989 em Nova Iorque, mostrando que os prejulgamentos antecipados baseados em estereótipos criados estão enraizados há muito tempo na sociedade como um todo, não se limitando ao Brasil.

Tais considerações nos levam a concluir que a sociedade como um todo precisa se desprender de perfis já traçados, necessita analisar cada caso em sua individualidade, buscando não cometer injustiças e condenações baseadas em impulsos meramente preconceituosos e equivocados.

Para os jovens que cometeram algum ato infracional, o estudo ainda buscou emergir nas medidas socioeducativas mais gravosas cumpridas na Fundação Casa, como semiliberdade e internação, a fim de mostrar sua eficiência em evitar a reincidência do jovem.

O que vislumbramos, foi um projeto rico em iniciativas pedagógicas - porém, sem a devida execução não permite a plena recuperação do internado. Destacamos também alguns pontos fragilizados no atendimento socioeducativo, que variam desde condições precárias de trabalho em determinados centros socioeducativos (sobrecarga em agentes socioeducativos).

No tocante à taxa de reincidência, notamos que esta é altíssima. Deduz-se então, dessa maneira, que a medida socioeducativa é apenas uma etapa no enfrentamento dos atos infracionais, devendo o acompanhamento do jovem transcender ao cumprimento da medida socioeducativa. Aliás, o acompanhamento da infância e adolescência deve ser sempre no sentido de impedir condutas desviantes, e para os que já se desviaram, deve ser no sentindo de dar continuação ao atendimento prestado durante o cumprimento da medida.

A Fundação Casa não irá reabilitar o jovem sem a devida participação da família e sociedade, pois o olhar atento e vigilante ao jovem deve continuar após a internação, e as oportunidades devem ser verdadeiramente concedidas pela família, Estado e sociedade. Os preconceitos devem ser deixados de lado, e ao ser reinserido na vida em comunidade, o jovem não pode ser tratado com desdém e distinção. As oportunidades de educação, formação, desenvolvimento devem ser equalizadas, e as diferenças socioeconômicas, drasticamente reduzidas.

As medidas socioeducativas atuam como um meio de remediar o desvio após sua consumação, o que nos remete ao fato de que as políticas públicas devem ser inclinadas no sentido de evitar o desvio de crianças e adolescentes, garantindo desse modo o desenvolvimento uniforme dos sujeitos de prioridade máxima.

As crianças e adolescentes são o futuro do país. 


\section{REFERENNCIAS}

ALBUQUERQUE, Daniel. Criminologia: Teorias do Consenso e Conflito. Jus Brasil, 2018. Disponível em: https://danalbuquerq.jusbrasil.com.br/artigos/601059200/criminologia-teorias-do-consenso-e-conflito. Acesso em: 7 out. 2019.

ARCOVERDE, Leo. 67,7\% dos jovens infratores em SP não frequentavam a escola quando foram detidos pela última vez. Globo News, São Paulo, 15 agosto 2018. Disponível em: https://g1.globo.com/sp/sao-paulo/noticia/2018/08/15/677-dos-jovens-infratores-em-sp-nao-frequentavam-a-escola-quando-foram-detidos-pela-ultima-vez.ghtml. Acesso em: 10 out. 2019.

BORGES, Éverton André Luçardo. Adolescente infrator e políticas públicas para ressocialização. In: Âmbito Jurídico, Rio Grande, XVI, n. 117, out 2013. Disponível em: https:/ / ambitojuridico.com.br/edicoes/revista-117/adolescente-infrator-e-politicas-publicas-para-ressocializacao/. Acesso em: 7 out. 2019.

BRANDÃO, Delano Câncio. Justiça Restaurativa no Brasil: Conceito, críticas e vantagens de um modelo alternativo de resolução de conflitos. Âmbito Jurídico, 2010. Disponível em: https://ambitojuridico.com.br/edicoes/revista-77/justica-restaurativa-no-brasil-conceito-criticas-e-vantagens-de-um-modelo-alternativo-de-resolucao-de-conflitos/.Acesso em: 06 novembro, 2020.

BRASIL, Constituição (1988). Constituição da República Federativa do Brasil. Disponível em: http://www.planalto.gov.br/ccivil_03/constituicao/Constituicao.htm. Acesso em: 7 out. 2019.

BRASIL, Lei no 8.069, de 13 jul. de 1990. Estatuto da Criança e do Adolescente. Disponível em: http://www.planalto.gov.br/ccivil_03/leis/18069.htm. Acesso em: 23 fev. 2020.

CALHAU, Lélio Braga. Resumo da Criminologia. 4ª ed. Rio de Janeiro: Impetus, 2009.

CARVALHO, Salo de. Antimanual de Criminologia. Rio de Janeiro: Lumen Juris, 2008.

GOUDINHO, Hawlison Carlos Santos. A Função do Estado e seu Papel na Ressocialização do Adolescente em Conflito com a Lei. Monografias Brasil e Escola, [20-?]. Disponível em: https://monografias.brasilescola.uol.com.br/direito/a-funcao-estado-seu-papel-na-ressocializacao-adolescente-conflito-com-a-lei.htm Acesso em: 8 out. 2019.

INSTITUTO SOU DA PAZ. Aí eu voltei para o corre: estudo da reincidência infracional do adolescente no estado de São Paulo. CONDECA, Secretaria de Desenvolvimento Social 
do Estado de São Paulo: São Paulo, 2018. Disponível em: http://www.mpsp.mp.br/portal/page/portal/documentacao_e_divulgacao/doc_biblioteca/bibli_servicos_produtos/ BibliotecaDigital/BibDigitalLivros/TodosOsLivros/ai_eu_voltei_pro_corre_2018.pdf. Acesso em: 26 abril 2020.

LEAL, César Barros. Prisão Crepúsculo de Uma Era. 2 ed. Belo Horizonte: Editora Del Rey, 2001.

MELO, Eduardo Rezende; EDNIR, Madza; YAZBEK, Vania Curi. Justiça Restaurativa e Comunitária em São Caetano do Sul: aprendendo com os conflitos a respeitar direitos e promover cidadania. São Paulo, 2008. Disponível em: http://www.tjsp.jus.br/Download/CoordenadoriaInfanciaJuventude/JusticaRestaurativa/SaoCaetanoSul/Publicacoes/ jr_sao-caetano_090209_bx.pdf. Acesso em: 25 abril 2020.

MOLINA, Antônio Garcia Pablos de. Tratado de Criminologia. $3^{\text {a }}$. ed. Valência: Tirant Lo Blanch, 2003.

PAIVA, Ilana Lemos de; SOUZA, Cândida; RODRIGUES, Daniela Bezerra (Org.). Justiça Juvenil: teoria e prática no sistema socioeducativo. Natal, 2014. Disponível em: <file:/ / C:/Users/Amandae/Downloads/Justi\%C3\%A7a\%20juvenil\%20(1).pdf. Acesso em: 18 abril 2020.

PENIDO, Egberto de Almeida. Justiça e Educação: parceria para a cidadania em Heliópolis/SP: a imprescindibilidade entre Justiça Restaurativa e Educação. 2008. Disponível em: http://www.juridica.mppr.mp.br/arquivos/File/MPRestaurativoEACulturadePaz/ Material_de_Apoio/Justica_e_Educacao_Egberto_Penido.pdf. Acesso em: 11 abril 2020.

PINTO, Renato Sócrates Gomes. A construção da justiça restaurativa no Brasil. Revista Paradigma, v. 1, n. 19, 4 nov. 2011. Disponível: http:/ / revistas.unaerp.br/paradigma/article/view/65/70. Acesso em: 10 abril. 2020.

RIBEIRO, Paulo Silvino. Rousseau e o contrato social. Brasil Escola. Disponível em: https:/ / brasilescola.uol.com.br/sociologia/rousseau-contrato-social.htm. Acesso em: 06 novembro 2020.

SÃO PAULO, Fundação Casa, 2015. Disponível em: http://www.fundacaocasa.sp.gov. br/View.aspx?title=a\%20funda\%C3\%A7\%C3\%A3o\&d=10. Acesso em: 26 abril 2020.

SHECAIRA, Sergio Salomão. Criminologia. Ed. Revista dos Tribunais. São Paulo, 2004.

SILVA, Marcelo Gomes. Ato Infracional e Garantias: Uma Crítica ao Direito Penal Juvenil. Florianópolis: Editora Conceito, 2008. 
TRINDADE, Jorge. Delinquência Juvenil: Uma abordagem Transdisciplinar. $2^{\mathrm{a}}$. ed. Porto Alegre: Livraria do Advogado, 1996.

VIEIRA, Henriqueta Scharf. Perfil do adolescente infrator no Estado de Santa Catarina. Cadernos do Ministério Público. Florianópolis: $n^{0}$ 03, Assessoria de Imprensa da Procuradoria Geral de Justiça, 1999.

VOLPI, Mário (Org.). O Adolescente e o Ato Infracional. 10 ed. São Paulo: Editora Cortez, 2015. 